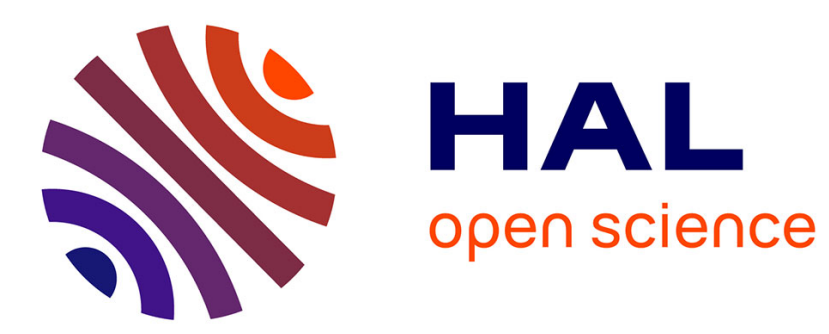

\title{
Depth profile of ferromagnetic layered samples studied with photothermally modulated magnetic resonance
}

\author{
J. Romano, A. Mansanares, E. da Silva, H. Vargas
}

\section{To cite this version:}

J. Romano, A. Mansanares, E. da Silva, H. Vargas. Depth profile of ferromagnetic layered samples studied with photothermally modulated magnetic resonance. Journal de Physique IV Proceedings, 1994, 04 (C7), pp.C7-667-C7-670. 10.1051/jp4:19947158 . jpa-00253217

\section{HAL Id: jpa-00253217 https://hal.science/jpa-00253217}

Submitted on 1 Jan 1994

HAL is a multi-disciplinary open access archive for the deposit and dissemination of scientific research documents, whether they are published or not. The documents may come from teaching and research institutions in France or abroad, or from public or private research centers.
L'archive ouverte pluridisciplinaire HAL, est destinée au dépôt et à la diffusion de documents scientifiques de niveau recherche, publiés ou non, émanant des établissements d'enseignement et de recherche français ou étrangers, des laboratoires publics ou privés. 


\title{
Depth profile of ferromagnetic layered samples studied with photothermally modulated magnetic resonance
}

\author{
J.A. Romano, A.M. Mansanares, E.C. da Silva and H. Vargas \\ Instituto de Física "Gleb Wataghin", Universidade Estadual de Campinas, UNICAMP, \\ 13083-970 Campinas, São Paulo, Brazil
}

\begin{abstract}
Depth profile analysis of a ferromagnetic layered sample composed of $\gamma-\mathrm{Fe}_{2} \mathrm{O}_{3}$ and $\mathrm{CrO}_{2}$ tapes were performed with photothermally modulated ferromagnetic resonance (PMFMR). Those analysis were done by using phase-resolved and modulation frequency variation methods. The experiments showed the advantages of this technique over the conventional one. The dependency of the detected signal on the modulation frequency was also studied for single layer samples, thus determining the microwave-absorbing layer thickness of the tapes.
\end{abstract}

\section{Introduction}

The photothermally modulated ferromagnetic resonance (PM-FMR) technique has been used as a magnetic imaging method [1,2] and even to investigate bulk properties of ferromagnetic materials [3]. On the other hand the photoacoustic (PA-FMR) and the photothermal-deflection (PD-FMR) resonance detection techniques were applied earlier for probing of subsurface structures of solids $[4,5]$. In this work we have used PM-FMR for a depth-profile analysis of layered ferromagnetic samples $\left(\gamma-\mathrm{Fe}_{2} \mathrm{O}_{3}\right.$ and $\mathrm{CrO}_{2}$ recording tapes) applying either the phase-resolved [6] or the frequency variation [7] methods. An estimate of the microwave-absorbing layer thickness for the one-layer tapes was obtained.

\section{Experimental}

\subsection{PM-FMR measurements}

The PM-FMR was measured using a Varian E-Line EPR spectrometer slightly modified, operating at $9.4 \mathrm{GHz}$ with a home-made [3] wall-less cylindrical $\mathrm{TE}_{011}$ cavity. In this case a laser beam modulated by a chopper could heat the sample inside the cavity without obstruction. The sample, a short strip cut of a recording magnetic tape, was positioned in the center of the cavity. The external magnetic field was parallel to the recording direction. The modulated beam spot, from an argon laser operating in multiline mode (458-514)nm, reaches the sample perpendicularly to its surface and was adjusted by a lens system to illuminate it completely. Unlikely the conventional case no field modulation is used in the PM-FMR experiments. In this case we used the described chopped laser beam for the thermal modulation.

\subsection{Samples}

The samples were obtained from commercial cassette recording tapes of iron(III)oxide and of chromium dioxide as ferromagnetic layers on a polyester backing. The layered sample consisted of a tape of $\gamma-\mathrm{Fe}_{2} \mathrm{O}_{3}\left(5 \mu \mathrm{m}\right.$ plus $15 \mu \mathrm{m}$ polyester) glued on a tape of $\mathrm{CrO}_{2}$ (same thickness as iron oxide). We have estimated the glue thickness as about $5 \mu \mathrm{m}$. The set was glued to a cardboard piece. The structure of the composed sample can be seen in the inset of Fig. 3 . 


\section{Results and Discussion}

PM-FMR spectra are shown in Fig. 1 and Fig. 2 for the $\gamma-\mathrm{Fe}_{2} \mathrm{O}_{3}$ and the $\mathrm{CrO}_{2}$ one layer tapes, respectively, and for $120 \mathrm{~mW}$ laser output power. The line shapes are typical and the behavior of both the PM-FMR amplitude and phase was already observed in this and in other ferromagnetic materials [8]. The minimum in the signal amplitude and the simultaneous $180^{\circ}$-phase inversion are in agreement with the fact that one is detecting a signal which is proportional to the value of the derivative of the dynamic susceptibility of the ferromagnet with respect to temperature.

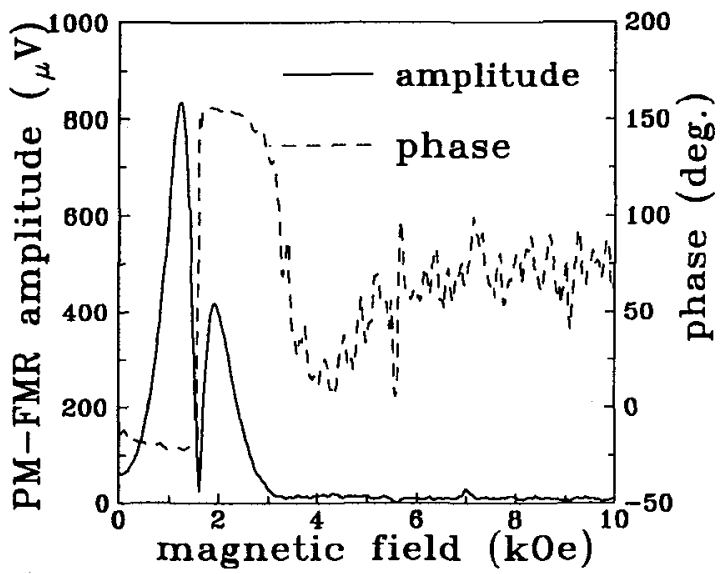

Fig. 1 - PM-FMR spectrum for the iron-oxide tape with $20 \mathrm{~mW}$ microwave power and $150 \mathrm{~Hz}$ of modulation frequency

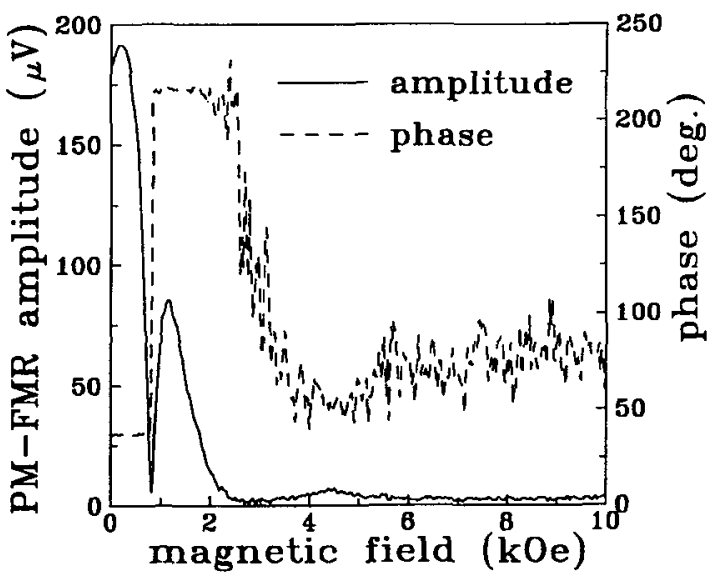

Fig. 2 - PM-FMR spectrum for the chromium dioxide tape with $5 \mathrm{~mW}$ microwave power and $2 \mathrm{KHz}$ modulation frequency
Figure 3 shows the PM-FMR spectra for a composed sample (see the inset in the figure) at different modulation frequencies. One can see, starting from the lower modulation frequency curve, that an increase in frequency leads to a decrease in the contribution of the chromium amplitude as it can be seen following the zero field amplitudes. The features of the spectrum at $510 \mathrm{~Hz}$ when compared with those of figure 1 suggest that in this case we have isolated the contribution of the iron oxide constituent from the superposed signal. In fact, if one assumes both surface light absorption and similar thermal properties for the constituents of the sample, let's say, with an average value of $1,0.10^{-3}$ $\mathrm{cm}^{2} / \mathrm{s}$ for the thermal diffusivity $\alpha$, one find $18 \mu \mathrm{m}$ and $8 \mu \mathrm{m}$ values for the thermal diffusion length $\mu$ for $97 \mathrm{~Hz}$ and $510 \mathrm{~Hz}$, respectively. This parameter represents the penetration depth of the thermal wave responsible for the modulation of the microwave absorption in the oxide ferromagnetic layers. Provided the microwave penetrates completely in the whole sample depth and considering the layered sample dimensions, those values for $\mu$ are consistent with our experimental observations: contribution of both ferromagnetic layers for the PM-FMR signal at low modulation frequency $(97 \mathrm{~Hz})$ and the increasing domination of the $\gamma-\mathrm{Fe}_{2} \mathrm{O}_{3}$ layer contribution as the frequency increases. Hence, we could separate the contribution of the upper layer applying the modulation frequency variation method.

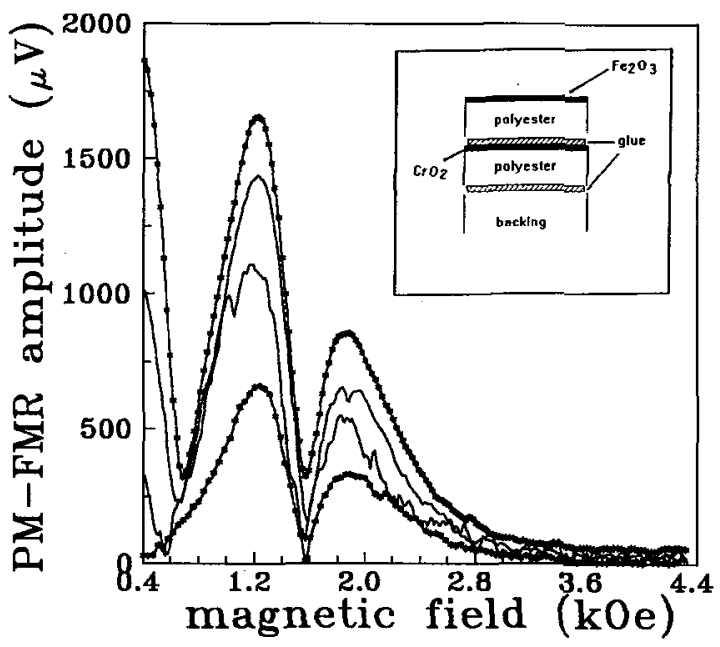

Fig. 3 - PM-FMR spectra for the composed sample. From the upper curve the modulation frequencies are $97,152,245$ and $510 \mathrm{~Hz}$. Microwave power was $10 \mathrm{~mW}$. The laser output power was $350 \mathrm{~mW}$. 
In order to proceed the separation of the contributions of both layers to the PM-FMR signal we have applied the phase-resolved method [6]. It consists in the use of the measured in-phase and outof-phase components of the signal (from the two ferromagnetic layers) at constant modulation frequency. Computer-aided projections of the total signal at different phase angles lead to angles for which the contributions of each layer vanish. In figure 4 are shown the PM-FMR spectra, obtained at $97 \mathrm{~Hz}$, for the composed sample. In figure $4 \mathrm{~b}$, for a phase angle of $274^{\circ}$, there is none contribution from the chromium dioxide layer. The spectrum fully resembles that one from iron-oxide single layer (Fig.1). On the other hand, figure 4c, for a phase angle of $180^{\circ}$, shows one spectrum in which the contribution of the iron-oxide layer is vanished and it resembles that one for chromium-oxide (Fig. 2). From these data one concludes that the $\gamma-\mathrm{Fe}_{2} \mathrm{O}_{3}$ and the $\mathrm{CrO}_{2}$ individual contributions to the total signal are at phase angles of $270^{\circ}$ and $184^{\circ}$, respectively. Hence, there is a phase-lag of $86^{\circ}$ between the signals from the two oxide layers. This difference arises from different thermal diffusion times for the heat reaching each oxide layer as, in our case, the layers are set at different depths.

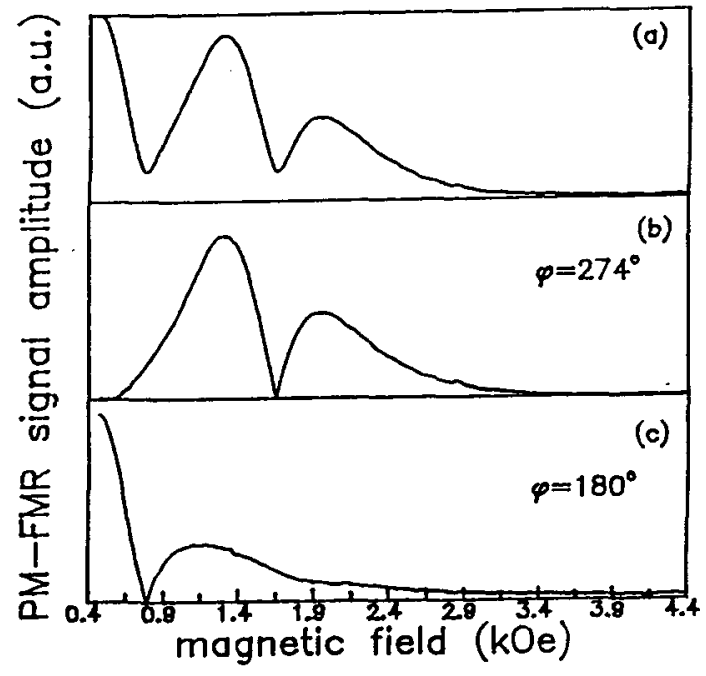

Fig. 4 - PM-FMR spectra from the composed sample at $10 \mathrm{~mW}$ microwave power and $350 \mathrm{~mW}$ laser output power: a) measured amplitude, b) projection at the phase angle $\left.\varphi=274^{\circ}, \mathrm{c}\right) \varphi=180^{\circ}$.
To estimate the microwave-absorbing layer thickness of the single-layer tapes we have assumed the one dimensional heat diffusion premise [7] with the configuration as shown in the inset of figure 5 . We have calculated the average temperature only in the ferromagnetic layer (thickness $\lambda$ ) where the microwave absorption occurs. Considering surface light absorption and the sample as thermally thick in the frequency region we dealt we found for the signal amplitude one expression proportional to

$$
\left\{\left[1-e^{-a \lambda} \cdot \cos (a \lambda)\right]^{2}+\left[e^{-a \lambda} \cdot \sin (a \lambda)\right]^{2}\right\}^{1 / 2}
$$

and for the signal phase a frequency dependence given as

$$
\tan ^{-1}\left[\frac{e^{-a \lambda} \cdot \sin (a \lambda)}{1-e^{-a \lambda} \cdot \cos (a \lambda)}\right]
$$

where

$$
a=1 / \mu=\left(\frac{\pi \mathrm{f}}{\alpha}\right)^{1 / 2} \text {, with } \mathrm{f} \text { the }
$$

modulation frequency.

We have carried out experiments with the external magnetic field at a value close to the maximum PMFMR amplitude (1.1kOe for iron and zero for chromium) and at $10 \mathrm{~mW}$ microwave power. The

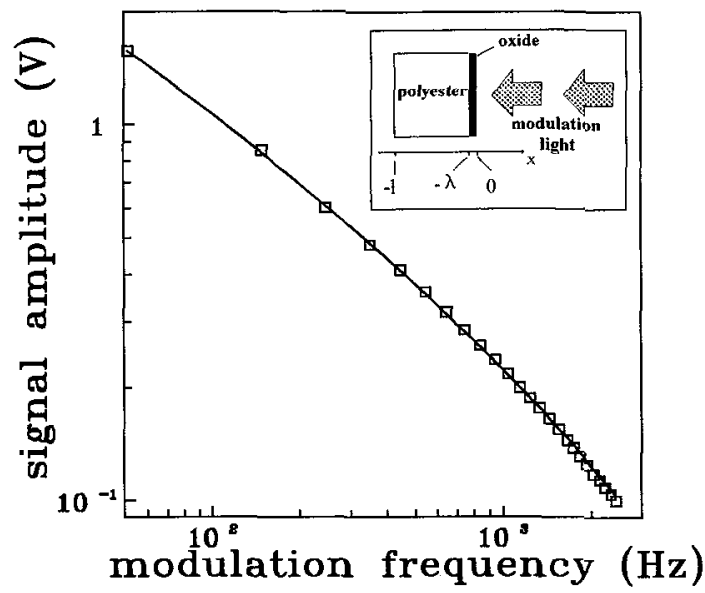

Fig. 5 - PM-FMR amplitude as a function of frequency for the $\gamma-\mathrm{Fe}_{2} \mathrm{O}_{3}$ tape. External magnetic field was $1.1 \mathrm{kOe}$. Laser output power: $100 \mathrm{~mW}$ 
behavior of the PM-FMR signal amplitude and phase as a function of the modulation frequency $f$ are shown in figures 5 and 6 (squares), respectively. From the fitting of the expression (1) to the experimental data (continuous curve, figure 5) we got the ferromagnetic layer thickness $\lambda$ for the $\gamma$ - $\mathrm{Fe}_{2} \mathrm{O}_{3}$ tape as $(5.8 \pm 0.4) \mu \mathrm{m}$. This is a value very close to the $5 \mu \mathrm{m}$ indicated by the manufacturer. For the sake of a check we used this value for $\lambda$ in the expression (2) for the phase (continuous curve) and got a fairly good agreement with the experimental data (squares), as shown in figure 6 .We have used the same procedure for the $\mathrm{CrO}_{2}$ tape and got (4.6 \pm 0.3$) \mu \mathrm{m}$ as the ferromagnetic layer thickness.

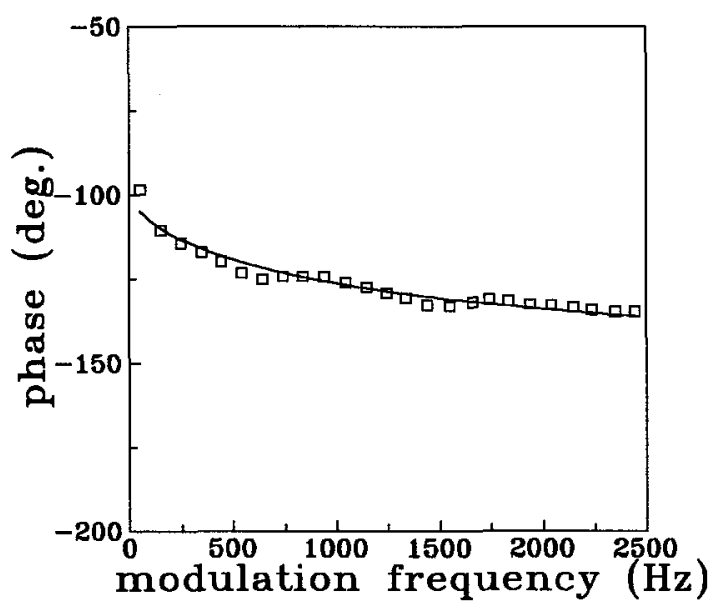

Fig. 6 - PM-FMR phase as a function of frequency for the $\gamma-\mathrm{Fe}_{2} \mathrm{O}_{3}$ tape. External magnetic field value was $1.1 \mathrm{kOe}$. Laser output power : $100 \mathrm{~mW}$.

\section{Conclusions}

We have demonstrated the possibility of depth profile investigations in magnetically inhomogeneous materials using the PM-FMR techniques. In the case of layered samples it was possible to isolate the contributions of each layer, as shown for the composed tape sample. An estimate of the thickness of the microwave absorbing layers is readily obtained with this technique. For its high sensitivity the PM-FMR technique is advantageous for these purposes compared with the other thermal wave resonance detection methods.

\section{Acknowledgments}

This work was supported by $\mathrm{CNPq}$ and FAPESP financial brazilian agencies.

\section{References}

[1] Orth T., Netzelmann U., Kordecki R. and Pelzl J., J. Magn. Magn. Mat. 83 (1990) 539-540

[2] Orth T., Netzelmann U. and Pelzl J., Appl. Phys. Lett.53(20) (1988) 1979-1981

[3] Medina Neto A. et allii, J. Magn. Magn. Mat. 128 (1993) $101-110$

[4] Netzlmann U. and Pelzl J., Appl. Phys. Lett. 44 (9) (1984) 854-856

[5] Netzlmann U., Pelzl J., Founier D. and Boccara A. C., Can. J. Phys. 64 (1986) 1307-1310

[6] Vargas H. and Miranda L. C. M., Physics Reports161(2) (1988) 44-101

[7] Rosencwaig A. and Gersho A., J. Appl. Phys. 47 (1976) 64

[8] Pelzl J. and Netzelmann U., in Topics in Current Physics 47, Springer-Verlag, Berlin (1989) 313 